\title{
Atmospheric phænomena seen at high field house, nottinghamshire, on the 20th and 21st of October 1844
}

\section{E.J. Lowe Esq.}

To cite this article: E.J. Lowe Esq. (1845) Atmospheric phænomena seen at high field house, nottinghamshire, on the 20th and 21st of October 1844, Philosophical Magazine Series 3 , 26:172, 264-267, DOI: 10.1080/14786444508645119

To link to this article: http://dx.doi.org/10.1080/14786444508645119

曲 Published online: 30 Apr 2009.

Submit your article to this journal $[\pi$

Џll Article views: 2

Q View related articles $\llbracket$ 
bustibles or Fossil Fuel, ranging from the True Coal up to the Tertiary Lignites and Peat or Turf, including Notices and Localities of most of the Mineral Bituminous Substances employed in Arts and Manufactures ; embracing, from official reports of the coal-producing countries, the respective amounts of their Production, Consumption and Commercial Distribution, together with their Prices, Tariffs, Currency, Duties and International Regulations,

\section{By Richard Cowling Taylor,}

PELLOW OF THE GEOLOGJCAJ SOCIETY OF LONDON; MEMBER OF THE AMERICAN PHIIOSOPHICAC SOCIETY, AND OF VARIOUS OTHER INSTITUTIONS.

This work being designed for a somewhat limited class of readers, it is necessary to ascertain, in the first instance, if a sale can be effected adequate to ensure the publisher from loss. As soon, therefore, as a sufficient number of names are obtained to justify the risk, the work will be irnmediately put to press.

The work will be comprised in a royal octavo volume of about 750 pages, illustrated with Maps, printed in the best manner, on fine paper, and haudsomely done up in embossed cloth, and will be furnished to subseribers at Five Dollars per copy.

In the meanwhile, the Author would be glad to receive, through the publisher, any useful communications in connection with the design of the work.

J. W. Moore, Publisher and Bookseller,
Philadelphia, January 1845. 138 Chestnut Street, Philadelphia.

XXXVIII. Intelligence and Miscellaneous Articles.

atmospheric PHenomena seen at high field house, NOTTINGHAMSHIRE, ON THE 20TH AND 21ST OF OCTOBER 1844. BY E. J. LOWE, EsQ.*

N the above-named days I noticed rare and interesting phænomena, which in my opinion are worthy of being recorded.

For two or three days prior to the 20 th the weather had been showery, with slight frosts at night.

20th.-Barometer, max. 29.35l ; min. 29.248. Thermometer, $\max .53^{\circ}$; min. $40^{\circ}$. Wind S.W. Mean amount of cloud $6 \frac{8}{10}$. Few cumuli ; fine sunshine a.m.; nimbus and cirrostrati ; dull, with few drops of rain at 5 p.m.

\section{Mock-Moon and Aurora Borealis.}

$8^{\mathrm{h}} 30^{\mathrm{m}}$ p.m.-A brilliant halo of $45^{\circ}$ in diameter encircled the moon. On turning to the direction of $N$. a very vivid and berutiful display of aurora borealis was disclosed to my sight. A broad stream of flame extended from the horizon through the constellations Auriga, Capella, Perseus, Cassiopeia, Cygnus and Lyra, and disappeared in the western horizon, near Serpentarius. This band flickered brightly for fifteen minutes, when it vanished.

- Communicated by the Author, whose former observations will be found in Phil. Mag. S. 3. vol. xxv. p, 390. 
$8^{\mathrm{h}} 40^{\mathrm{m}}$.-A mock-moon of a pale silvery hue shone out of the lunar halo on the N.E. side, being on the horizontal level of the moon. A flame of aurora crossed (through the broad flame) from the pole star through Perseus.

$8^{\mathrm{h}} 45^{\mathrm{m}}$. - Another stream of light extended through Ursa Major and Ursa Minor to Draco. At this time the flame from the polar star to Perseus was very vivid. During the whole of this display, the horizon from N.E. round by N. to N.W. appeared one continual flame, not glaring upwards, but along the horizon: therefore the chief portion of light was reflected from below. Paraselena still visible.

$8^{\mathrm{h}} 50^{\mathrm{m}}$. - The mock-moon disappeared. The lunar halo remained all night.

$9^{\mathrm{h}} 0^{\mathrm{m}}$. - The aurora borealis, comparatively speaking, vanished, but yet there was a slight glimmering now and then which would hardly have been noticed had not the phænomenon been perceived before.

$11^{\mathrm{h}} 0^{\mathrm{m}}$.-The stars shone through a haze, which gave them the appearance of being surrounded by burrs.

October 21 st.-Few cumuli and cirri; fine a.m., dull p.m.; rainy night. Barometer, max. 29.572 ; min. 29.241 , rising. Thermometer, $\max .55^{\circ}$; min. $39^{\circ}$ : 9 a.m. $47^{\circ} ; 9$ p.m. $46 t^{\circ}$. Hygrometer, 9 a.m. $40^{\circ} ; 9$ p.m. $40^{\circ}$. Wind S.E. Mean force of wind 2 ; mean amount of cloud 7 .

\section{Parhelia, \&c.}

11 a.m.-A highly prismatic halo, $\mathrm{C} \mathrm{C}$, of $45^{\circ}$ in diameter surrounded the sun; the clouds around were thin cirri; those on the horizon cumuli.

$11^{\mathrm{h}} 30^{\mathrm{m}}$ a.m.- An inverted arc of an iris, D D, resting on the sum-

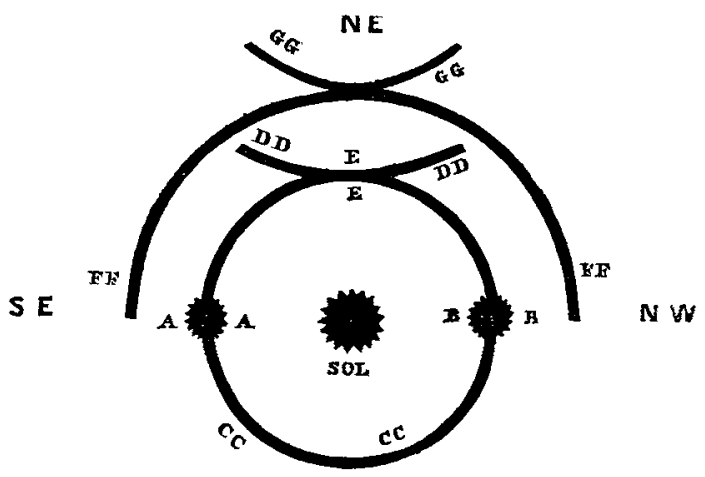

Horizon

s w

mit of the halo $\mathrm{CC}$ appeared. Had the iris DD been a perfect Phil. Mag. S. 3. Vol. 26. No. 172. March 1845. 
circle, it would have had a diameter of $96 \frac{1}{2}^{\circ}$. At the point $E$ of the iris $\mathrm{DD}$, which cut the halo $\mathrm{C} \mathrm{C}$, the light was almost as brilliant as from the sun itself. This lasted till $0^{\mathrm{h}} 15^{\mathrm{m}}$ p.m., when it faded away, together with the halo $\mathrm{C} \mathrm{C}$.

$1^{\mathrm{h}} 15^{\mathrm{m}}$.-The halo $\mathrm{C} \mathrm{C}$ and inverted arc of iris D D again appeared; the latter was very distinctly prismatic, having the red colour next the sun.

From this until about 2 p.m. no change worthy of mention, except that the inverted arc of the iris DD kept continually increasing and decreasing in brightness, and every now and then was so brilliant as scarcely to be looked at.

$2^{\mathrm{h}} 1^{\mathrm{m}}$.-A parhelion, A A, of a silvery colour appeared in the S.E. side of the halo C C and on the horizontal level of the sun.

$2^{\mathrm{h}} 5^{\mathrm{m}}$.-Mock-sun A A vanished. The portion $\mathrm{EE}$ of the inverted iris $\mathrm{DD}$ that cut the halo $\mathrm{CC}$ was extremely bright.

$2^{\mathrm{h}} 9^{\mathrm{m}}$. - A halo, or more properly speaking an iris $\mathrm{F} \mathrm{F}$, became visible, surrounding the upper or N.E. half of the halo $\mathrm{C} \mathrm{C}$ at a distance of $15^{\circ}$ from it; this was of a silvery hue.

$2^{\mathrm{h}} 10^{\mathrm{m}}$.-Another inverted arc of an iris, G G, appeared at the vertex of the iris F F ; had this described a circle its diameter would have been $64^{\circ}$; the inverted iris D D was brilliant in the highest degree. [Both the inverted irises, DD and G G, were situated on the halo $\mathrm{C} \mathrm{C}$ and iris F F, and opened in a direction to the N.E.]

$2^{\mathrm{h}} 15^{\mathrm{m}}$.-Atmosphere very dense. The iris F F and inverted iris G G at its vertex, together with the S.E. side of the balo C C, disappeared. The inverted iris, D D, was very brilliant. Few cirrostrati floated below the sun, and cumuli round the horizon.

$2^{\mathrm{h}} 18^{\mathrm{m}}$.- Halo C C very indistinct, but the inverted iris D D at its summit still very bright.

$2^{\mathrm{h}} 26^{\mathrm{m}}$. - Inverted iris D D vanished. The disappearance of this inverted iris was rather singular, for in most instances the brightest portion of the phænomenon continues to the last. A faint parhelion, B B, at this time was visible in the N.W. side of the halo C C, and likewise on the horizontal level of the sun. This lasted till $2^{\mathrm{h}} 30^{\mathrm{m}}$, when all vanished.

$2^{\mathrm{h}} 30^{\mathrm{m}}$. - Scud and cirrostrati covered the whole visible surface of the sky, and became more dense every minute. The clouds were evidently formed on the spot, and plainly by the vapours reaching the cold current. Overcast close evening; rainy night.

Excepting the halo C C and inverted iris D D (which were prismatic), the colour was pale silver throughout.

It is somewhat remarkable that I should have been fortunate enough in little more than a year to have seen three such beautiful and rare atmospheric phænomena as those I have described:- the first, parhelia seen at Derby on the 16 th of June 1843 ; second, paraselenæ seen at High Field House, May 1, 1844 ; and last, parhelia seen at High Field House, October 21, 1844. But it is recorded that John Hevelius was still more fortunate, for he in the short space of eleven months witnessed at Dantzic four of these very rare phænomena :-the first, paraselenæ on March 30,1660; second, parbelia, 
April 6, 1660; third, paraselenæ, December 17, 1660; and fourth, parhelia, February 20, 1661. That noticed by Hevelius on the 30th of March, 1660, was very similar to the one seen at High Field House on the 21 st of October, 1844 ; only this was parhelia, and that de. scribed by the Polish astronomer paraselenæ.

Since the appearance of the parhelia on the 21st of October, 1844, we have had a very considerable fall of rain.

High Field House, Lenton, Nottinghamshire, $\quad$ E. J. Lowr. November 8,1844 .

Distillation of BUTYRATE OF Lime. BY M. G. CHANCEL.

When a small quantity of this salt, anhydrous and pure, is cautiously heated, it is quickly decomposed into carbonic acid, which remains combined with the lime, and a volatile oil which distils; this oil is butyrone, nearly pure and only slightly coloured; the residue consists entirely of carbonate of lime, which is perfectly white and pure. When care is taken not to exceed the temperature requisite for the formation of butyrone, with a quantity not exceeding about 100 grains, not the slightest trace of charcoal is deposited.

Most commonly no gas is evolved, unless the heat be too great; in this case the quantity of gaseous products amounts to 3 or 4 per cent. of the butyrate acted upon. The greater portion is formed of bicarburetted hydrogen absorbable by sulphuric acid.

It is worthy of remark, that, provided anhydrous butyrate be employed, no water is in any case disengaged, and yet it is well known that the distillation of organic matter is almost always accompanied with the formation of some water at the expense of the elements of the organic body.

When, however, considerable quantities of the butyrate of lime are submitted to distillation, the operation is far from being as simple; in this case the author could not avoid the deposition of some charcoal, and the liquid products obtained were always considerably coloured; this may be attributed to the ulterior decomposition of a portion of the butyrone formed, on account of the unequal distribution of the heat throughout the mass. In this case there is thus formed a mixture of several liquid substances, in which butyrone is the prevailing one.

In several distillations 100 parts of anhydrous butyrate of lime yielded from 42 to 43 parts of rough butyrone.

\section{Preparation of pure Butyrone.}

When the above-described impure liquid is submitted to distillation, the boiling-point, which is at first under $212^{\circ}$, soon rises nearly to $284^{\circ}$; the fluid which rises between $284^{\circ}$ and $293^{\circ}$ is to be kept separate, and is entirely butyrone; the products which are collected previously and subsequently are mixtures of butyrone, and two peculiar substances, one of which distils below $212^{\circ}$ and the other at above $320^{\circ}$; the butyrone distilled between $284^{\circ}$ and $293^{\circ}$, once redistilled, has a constant boiling-point, and may be regarded as pure butyrone. 